\title{
Perspectivas para Cairo+20: como avançar na discussão sobre população e desenvolvimento
}

\author{
Ana Amélia Camarano*
}

\section{Introdução}

Em 2014, a Conferência Internacional de População e Desenvolvimento (CIPD), conhecida como Conferência do Cairo, completará 20 anos. Seu principal objetivo foi o de consensuar uma posição sobre a relação população e desenvolvimento para os 20 anos seguintes, expressa em um programa de ação.

Entre a primeira conferência, ocorrida em 1954, e a CIPD mais três conferências foram realizadas. As duas primeiras tiveram caráter técnico-científico, mas contou com a participação de países desenvolvidos e de economia planejada e dos países em desenvolvimento como observadores. Embora o tema destas fosse o binômio população e desenvolvimento, suas agendas foram pautadas, com formatos e justificativas diferentes, pelo temor da fecundidade elevada dos países do Hemisfério Sul.

Quando a primeira conferência aconteceu, a população desses países, aí incluído o Brasil, experimentavam taxas de crescimento elevadas, dadas a alta fecundidade e a redução da mortalidade infantil. Essas populações cresciam a taxas médias de aproximadamente 3\% ao ano, o que poderia dobrar seu contingente em 23 anos.

Desde então, a realidade demográfica mudou muito. A fecundidade declinou expressivamente em quase todos esses países e a pobreza continua sendo um desafio, embora tenha diminuído em parte deles. O medo da "explosão" demográfica pode ser substituído pelo da "implosão".

O objetivo desta nota é discutir alguns pontos apresentados no Programa de Ação de 1994 à luz da nova realidade demográfica.

\footnotetext{
* Instituto de Pesquisa Econômica Aplicada - Ipea, Brasília-DF, Brasil (ana.camarano@ipea.gov.br).
} 


\section{O binômio população e desenvolvimento nas Conferências de População}

As relações entre crescimento populacional e desenvolvimento econômico têm sido discutidas desde Malthus e referem-se tanto aos impactos do crescimento populacional e distribuição etária sobre o crescimento econômico e a distribuição de renda, quanto ao inverso. Essa discussão ganhou força nos anos 1950 no Ocidente, em especial nos Estados Unidos. A visão dominante enfatizava os efeitos negativos do rápido crescimento da população no crescimento econômico dos países menos desenvolvidos. Assim, a implementação de políticas de planejamento familiar eram vistas como instrumentos importantes para o alcance do crescimento econômico (SZRETER, 1993). Neste contexto, aconteceu a primeira conferência.

Esse debate evoluiu marcado por muitas controvérsias. Nas conferências, a população sempre foi vista como um "problema". Os "problemas" vestiam diferentes roupagens, que variavam conforme o momento: fome, pobreza, aumento do consumo e diminuição do investimento, degradação ambiental e dominação das mulheres. Para Furedi (1998), interpretar problemas sociais sob o prisma da população é uma estratégia para desviar a atenção dos problemas reais. Pergunta-se se as conferências são de população, para a população ou antipopulação?

A Conferência do Cairo teve como objetivo a queda das taxas de crescimento populacional e a estabilização da população mundial em níveis compativeis com os recursos do planeta. Desta vez, sob a ótica dos chamados direitos reprodutivos, que podem ser traduzidos como direitos não reprodutivos. Duas racionalidades para o "problema populacional" foram colocadas: empoderamento da mulher e proteção ambiental.

$\mathrm{Na}$ filosofia das conferências, acredita-se que o interesse deveria ser o crescimento populacional, ou seja, a interação entre natalidade e mortalidade. Porém, pouca importância foi dada ao comportamento da mortalidade, variável determinante do processo reprodutivo e de crescimento.

Reconhece-se que a população não pode crescer sem limites. Como todas as sociedades investem na redução da mortalidade, as políticas populacionais almejam a redução do crescimento populacional via diminuição da fecundidade (CLELAND, 1994). Mas esta é uma questão ambígua, pois as sociedades desejam a reprodução em algum grau, para garantir sua reposição.

Novos fenômenos demográficos presentes em 1994, como envelhecimento, juventude, migração internacional, sobremortalidade masculina e fecundidade abaixo dos níveis de reposição, receberam pouca atenção na CIPD. Todos eles guardam estreita relação com o processo de desenvolvimento econômico.

Em agosto de 2013, realizou-se a primeira Conferência Regional de População e Desenvolvimento da América Latina e do Caribe, onde foi elaborado um documento para subsidiar o documento final do Cairo+20. Esse apresentou um grande avanço em várias áreas, destacando-se a maior importância dada ao envelhecimento populacional (CEPAL, 2013). 
Sintetizando, parece que o binômio população-desenvolvimento era traduzido por propostas de ações que visavam estimular a redução da fecundidade para assim alcançar o desenvolvimento econômico e a redução da pobreza, da degradação ambiental e da dominação da mulher.

\section{A nova realidade demográfica}

O paradigma demográfico atual é bastante diferente do observado nos anos 1950: proliferação de famílias de filho único e de casais sem filhos; esperança de vida ao nascer e nas idades avançadas em rápido crescimento; diminuição do ritmo de crescimento da população; redução da força de trabalho; e envelhecimento.

A maioria dos países envelheceu, o que coloca novos desafios para os países em desenvolvimento que se somam aos já existentes, como o atendimento das necessidades sociais básicas - educação e saúde, por exemplo. Os avanços da tecnologia médica permitem uma intervenção no ciclo da vida em todas as suas etapas, do nascimento até a morte: da reprodução assistida e clonagem até a aceleração ou prolongamento da morte. São avanços que interferem na dinâmica demográfica.

A literatura sobre a transição demográfica sugeria que a população se estabilizaria quando a fecundidade atingisse os níveis de reposição, ficando constante neste patamar (KIRK, 1944). Falava-se, inclusive, em “fim da transição demográfica”. Entretanto, a fecundidade de reposição provou ser apenas um ponto no caminho de baixíssimos níveis de fecundidade (REHER, 2007).

Dos 202 países do mundo que se têm informações, 80 apresentavam, em 2012, taxas de fecundidade abaixo de 2,1 filhos por mulher, o que garantiria a reposição de suas populações. Destes, 50\% são europeus e 18\% estão na América Latina. ${ }^{1}$ Entre 2000-2004, a taxa de fecundidade total da América Latina e do Caribe atingiu 60\% do valor máximo historicamente observado (REHER, 2007).

Pesquisa do Instituto Max Planck apontou que as taxas de natalidade de 28 países europeus estão em queda desde 2008, o que pode estar relacionado ao aumento do desemprego. Afetou mais os países do sul do continente, como Espanha, onde o número de nascimentos por mulher diminuiu 8\% entre 2008 e 2011 . 0 mesmo aconteceu na Hungria, Irlanda e Croácia. ${ }^{2}$

Não se acredita que a fecundidade aumentará em um futuro próximo. A baixíssima fecundidade veio para ficar (VAN DE KAA, 1987; LESTAHGUE, 2010). Ter filhos na atualidade é uma expressão de confiança no futuro, na segurança da vida que um indivíduo pode esperar para seus filhos. Esta confiança é afetada pelas restrições políticas e econômicas. Além disso, a redução dos diferenciais de gênero na vida pública e privada tem minimizado a importância da maternidade para as mulheres. Novos valores que fazem parte da sociedade atual contribuem para uma baixa fecundidade: consumerismo; satisfação no trabalho para as mulheres; necessidade de duas rendas em uma família; e percepção entre muitos casais que

\footnotetext{
1 Disponível em: 〈www.un.org〉. Acesso em: 15 jul. 2013.

2 Disponível em: 〈www.demogr.mpg.de/eng〉. Acesso em: 15 jul. 2013.
} 
"ter filhos é muito caro" (DYSON, 2001). Níveis muito baixos de fecundidade sinalizam para mudanças sociais importantes e parecem fazer parte do mundo pós-moderno (REHER, 2007).

Mesmo que a fecundidade aumente em um futuro próximo, é improvável que o declínio populacional seja abortado, pois a redução dos nascimentos já resultou em uma menor coorte de mães. Vivencia-se o início de uma grande mudança: um longo período de rápido crescimento populacional sucedido por um de redução. Só foram observados dois períodos de declínio populacional prolongado no último milênio. Um afetou a Europa (peste negra) e o outro, as Américas (extermínio da população indígena). Ambos resultaram do aumento da mortalidade. Neste século, a queda da fecundidade é a determinante-chave, o que torna a situação mais preocupante. Este período de decréscimo pode ser prolongado, pelo momentum populacional negativo (REHER, 2007).

No Brasil, a taxa intrínseca de crescimento aponta que, no médio prazo, a taxa de crescimento populacional tenderá a valores próximos a -0,6\% a.a. 0 processo de declínio da população brasileira deverá se iniciar por volta de 2030, quando a população atingir aproximadamente 208 milhões de habitantes (CAMARANO; KANSO; FERNANDES, 2013). Ou seja, a redução do crescimento populacional já está embutida na dinâmica atual da população brasileira.

O decréscimo de população conjuntamente com envelhecimento é um fato novo na história. A literatura tem dado muito mais atenção às questões do envelhecimento do que à redução da população, principalmente no que diz respeito às suas implicações para a sustentabilidade dos sistemas de seguridade social.

Acredita-se que nenhum país deseje o declínio populacional, pois isto tem implicações de várias ordens. A primeira é a perda de poder econômico e geopolítico em relação a países onde a população ainda cresce. Citam-se, ainda, a redução da força de trabalho e a perda de apoios (financeiro e instrumental) para a população dependente, as deseconomias de escala, etc. Historicamente, “uma população numerosa e bem alimentada” era considerada o sinal de uma sociedade bem-sucedida. Períodos de declínio são vistos como resultado da incapacidade da sociedade de funcionar adequadamente. Pergunta-se se o futuro da humanidade será de sucesso ou de fracasso (REHER, 2007).

Embora o fator desencadeador do envelhecimento e da diminuição populacional - a redução da fecundidade - seja comum aos dois processos, a dinâmica e os efeitos de cada um são diferentes. Fecundidade de sub-reposição envelhece a população até que a nova estrutura etária se estabilize. Já o declínio sustentável da população pode ser substancial. No longo prazo, reduções da mortalidade exercerão um papel importante em ambos os processos, o que requer aumentar a sua importância na avaliação do Programa de Ação.

No momento de se repensar esse programa, pergunta-se se as suas deliberações continuam pertinentes. O menor crescimento populacional está gerando maior crescimento econômico, menos pobreza, menos degradação ambiental e/ou maior status para as mulheres? O novo contexto demográfico demanda repensar a relação população e desenvolvimento econômico. 


\section{Pensando em Cairo+20}

Diante do novo contexto, pergunta-se qual é o "problema populacional" do momento, que justificaria uma nova conferência. Independente de existir ou não um "problema populacional," pode-se dizer que as questões demográficas atuais - fecundidade de sub-reposição, diminuição da população, envelhecimento e degradação ambiental - são bastante diferentes das que nortearam as conferências anteriores. Considerá-las em uma nova conferência significa ampliar o escopo dos direitos reprodutivos. Mais atenção deve ser dada ao papel desempenhado pela mortalidade no crescimento populacional, no processo reprodutivo e no envelhecimento da população idosa.

Sugere-se que o direito à reprodução seja visto como um dos mecanismos para garantir a continuação da espécie humana. Isto significa incluir incentivos ao aumento da fecundidade e à redução da mortalidade infantil e da mortalidade masculina por causas externas. Mas devese considerar o direito a uma morte digna. Alguns países já descriminalizaram a eutanásia. Como o aborto, esta é uma questão que deve ser incluída no escopo dos direitos reprodutivos.

Finalizando, ao contrário do que afirmava McNicoll (1992, p. 399) de que a "calma voltou na Demografia”, ou que parecia faltar "excitação na Demografia”, 3 há várias questões na agenda social para estimular a imaginação e a criatividade dos demógrafos. São diferentes das anteriores, mas também excitantes e polêmicas.

\section{Referências}

CAMARANO, A. A.; KANSO, S.; FERNANDES, D. A população brasileira e seus movimentos ao longo do século XX. 2013. Mimeografado.

CEPAL. Consenso de Montevideo sobre población y desarrollo. Documentos de trabajo. Montevidéu, 2013. Disponivel em: 〈http://www.cepal.org/celade/noticias/documentosdetrabajo/9/50709/2013596-montevideo_consensus_pyd.pdf>. Acesso em: 16 ago. 2013.

CLELAND, J. Different pathways to demographic transition. In: SMITH, F. G. (Ed.). Population: the complex reality. Golden, Co.: North American Press, 1994.

DYSON, T. A partial theory of world development: the neglected role of demographic transition in the shaping of modern society. Int. J. Popul. Geogr, n. 7, p. 67-90, 2001.

FUREDI, F. Populations \& development: a critical introduction. New York: St. Martin's Press, 1998.

KIRK, D. Population changes and the postwar world. American Sociological Review, v. 9, n. 1 , p. 28-35, 1944.

LESTHAEGUE, R. The unfolding story of the Second Demographic Transition. Population and Development Review, v. 36, n. 2, p. 211-251, 2010.

MCNICOLL, N. The agenda of population studies: a commentary and a complaint. Population and Development Review, v. 18, n. 3, p. 399-420, 1992.

REHER, D. S. Towards long-term population decline: a discussion of relevant issues. Eur J Population, V. 23, n. 2, p. 189-207, 2007.

\footnotetext{
${ }^{3}$ McNicoll (1992) referia-se ao fim do debate entre controlistas e pró-natalistas.
} 
SZRETER, S. The idea of demographic transition and the study of fertility change: a critical intellectual history. Population and Development Review, v. 19, n. 3, p. 659-701, 1993.

VAN DE KAA, D. J. Europe's second demographic transition. Population Bulletin, Washington, v. 42, n. 2, p. 1-59, 1987.

\section{Autora}

Ana Amélia Camarano é PhD em Population Studies pela London School of Economics. Pesquisadora do Instituto de Pesquisa Econômica Aplicada - Ipea.

Recebido para publicação em 11/09/2013 Aceito para publicação em 10/10/2013 